\title{
A Proposed E-Learning System for Arabic Sign Language
}

\author{
A. S. Elons ${ }^{* 1}$, M. F. Tolba ${ }^{* 2}$ \\ * Scientific Computing Department- Faculty of Computers and \\ Information Sciences- Ain Shams University-Cairo-Egypt \\ ${ }^{1}$ ahmed. new80@hotmail.com \\ ?2fahmytolba@gmail.com
}

\begin{abstract}
There is no doubt that the Middle East region suffers from many educational problems especially within the field of people with disabilities. Hearing Impaired (HI) people (especially children) have the right to a quality education, with the same content and to the same academic standards as hearing people. HI education is the education of students with various hearing levels in a way that addresses the students' individual differences and needs. Unfortunately, the courses in different education levels are not available to HI students in a form they can understand and there are also too few qualified teachers that teach in $\mathrm{HI}$ Language Schools. The proposed solution is to provide an eLearning solution that leverages the current IT infrastructures and presents enhanced pedagogical aspects of the e-Course for Arabic Sign Language (ArSL). The proposed system modules will be hosted on a public cloud for security and resource management purposes and will be the base for constructing an e-Learning center for hearing impaired individual education. 3 modules have been built; sign to text, text to sign and student scoring. The system is initially built for 50 signs and two students were exposed to the system. Translation accuracy reached $88 \%$. The student can use either a digital camera or leap motion for signing.
\end{abstract}

Key words: Language Knowledge, Arabic Sign Language (ArSL), E-Learning, Hearing Impaired (HI), Sign Language Recognition and Sign Language Synthesis.

\section{INTRODUCTION}

For many (HI) individuals, sign language is the principle means of communication. The main problem is that few people (HI) ever learn to sign. Another problem is that many of them (HI people) are also not able to read or write a spoken language. These problems increase the isolation of HI people; they may be confined in many of their interactions to communicate only with other HI people. In Egypt, the number of HI people, according to the last study done by the "Central Agency for Public Mobilization and Statistics" in 2010, is around 4 million [1] and 70\% of this number can't read or write Arabic language. (HI) citizens have the right to get an equal education level to that of normal hearing individuals. (HI) individuals especially HI students; usually obtain the same level of mental ability as normal hearing students in terms of studying. The term 'deaf and dumb' is no longer used, since the hearing impaired students are only lacking their hearing capability not their mental level, Schwartz [2]. However, teachers or instructors should consider that techniques for $\mathrm{HI}$ children must be different than those from normal hearing peers for the same content. Thus, the technology usage and customization are vital in preparing HI students with an appropriate learning environment, since by using technology, the HI students can access sound in their own suitable way. The - e-Learning environment is one of the most commonly used techniques for educational objectives, including education for HI students. However, most eLearning environments available are not particularly useful to HI students due to features which are lacking in terms of adaptability. The goal of this project is to build a cloud based tutoring system in real-time that's credible and interactive with ArSL tutoring systems. This system can be considered as a first step towards building a national e- Learning system for all primary school levels. A pre-requisite step towards building the tutoring system is unifying the ArSL among HI students and teachers. The system development starts with building a benchmark database for standard ArSL. The proposed system is shown in Fig.1:

- $\quad$ Can work in two modes, teacher based mode and automatic mode.

- $\quad$ Provides the child with the text, physical meaning and ArSL signs.

- $\quad$ Can provide an assessment tool to measure the child's capabilities and learning rate.

- $\quad$ Can also help the non-HI family members to learn ArSL to be able to communicate better with HI children. 


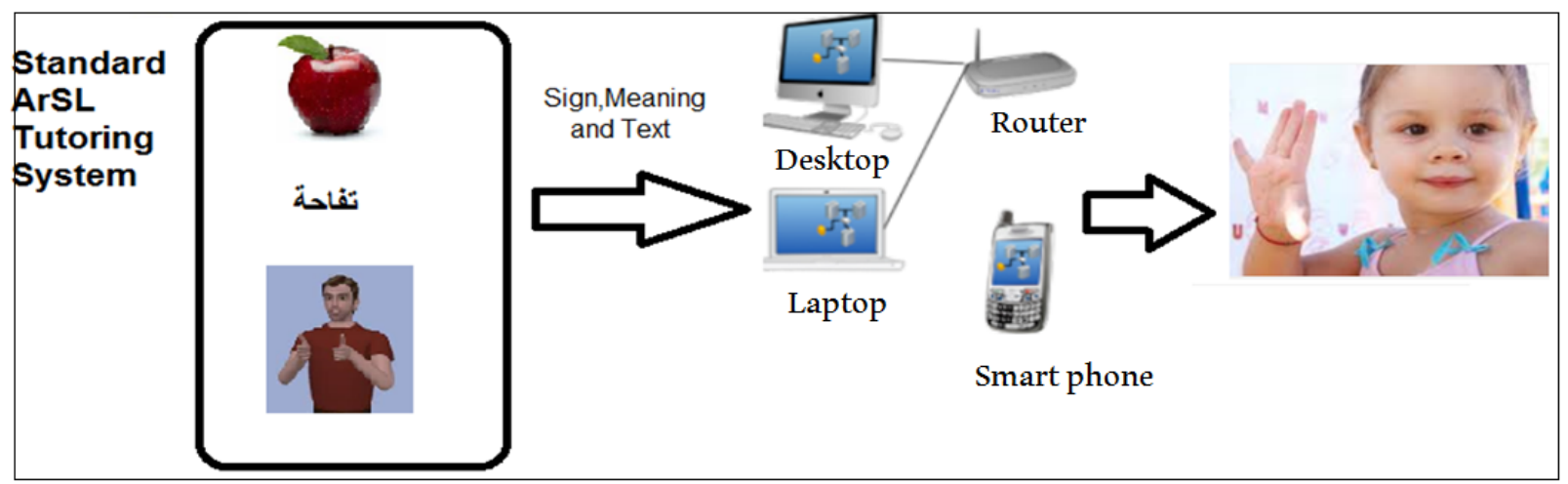

Figure 1: The proposed system

\section{LITERATURE REVIEW}

Contrary to common sense among the public, Sign Language is not universal. Where people speak a different phonetic language, there is also a different Sign Language. Besides the locality nature of sign languages, Arabic Sign Language (ArSL) is not standard. Recently in 2005 [3], the standard ArSL dictionary was accredited and publically published to the Arabian HI community. Our research has shown that very few research attempts worldwide succeeded to develop practical and public efficient products. None of these attempts succeeded to develop a practical commercial product for Arabic sign language. The following table illustrates some research projects which translate from sign language to spoken or vice versa.

TABLE 1

EXAMPLES OF THE PROJECT DIRECTED FOR HI INDIVIDUALS

\begin{tabular}{|l|c|l|l|l|l|l|}
\hline Project Name & $\begin{array}{c}\text { Translation } \\
\text { direction }\end{array}$ & $\begin{array}{l}\text { Video- } \\
\text { Based }\end{array}$ & $\begin{array}{l}\text { Educational } \\
\text { Tool }\end{array}$ & Dictionary & $\begin{array}{c}\text { Data- } \\
\text { size }\end{array}$ & Commercial \\
\hline i Communicator & both & Yes & Yes & Yes & 90 & No \\
\hline eSIGN & Text to sign & - & yes & No & 112 & No \\
\hline SignGenius & Text to sign & - & Yes & No & 198 & No \\
\hline ASL & Text to Sign & - & Yes & Yes & 214 & Yes \\
\hline The Sign2 & Sign to text & Yes & No & Yes & 338 & No \\
\hline
\end{tabular}

Beside existing products for foreign languages, Arabian researchers did and still do potential trials to build realistic ArSL translators. Unfortunately, these trials did not exceed the laboratory work. Mohandes [4] introduced a method for automatic recognition of Arabic sign language letters. For feature extraction, Hu's moments were used followed by support vector machines (SVMs) for classification and a correct recognition rate of $87 \%$ was achieved. El-Bendary et al [5] developed a sign language recognition system for the Arabic alphabet, achieving an accuracy of 91.3\%. In their system, images of bare hands are processed. The input to the system is a set of features extracted from a video of signs and the output is in simple text. For each frame, the hand outline is first extracted. Using the centroid as a reference point, the distances to the outline of the hand covering 180 degree are extracted as a 50-D feature vector, these features are rotation, scale and translation invariant. In the feature segmentation stage, they assumed a small pause between letters. Such pauses are used to separate the letter numbers and the related video frames. The signs of the alphabet are divided into three different categories before feature extraction. At the recognition stage, a multi-layer perceptron neural network and a minimum distance classifier were used. Elons et al. [6] proposed a pulse coupled neural network (PCNN) to compensate for lighting non-homogeneity and background brightness. The proposed system showed invariance under geometrical transforms with bright background and lighting conditions achieving a recognition accuracy of $90 \%$. Al Mashagba et al. [7] developed an automatic isolated word recognition system using two different colored gloves and an additional colored reference mark on the head. After extracting the three colored regions, five geometric features are extracted from any given video sequence. These features are: Hand angle velocity, hand horizontal velocity, hand 
vertical velocity, hand horizontal positions to the center of the head and hand vertical positions to the center of the head. A time delay neural network is used in the recognition stage, achieving a recognition accuracy of $77.4 \%$. All these research trials achieved acceptable results on a limited dataset with specific constraints. Our review has shown that very few research attempts worldwide have succeeded to develop practical and public efficient products for the usage of the elearning environment for hearing impaired students. None of these attempts addressed ArSL. Table 2 illustrates some of these trials.

TABLE 2

SOME EXISTING E-LEARNING PROJECTS FOR DISABLED PERSONS

\begin{tabular}{|c|c|c|c|c|c|}
\hline Authors & $\begin{array}{l}\text { Target } \\
\text { Group }\end{array}$ & Content & Approach & Year & Language \\
\hline $\begin{array}{l}\text { Drigas, A.S., } \\
\text { Kouremenos, D. } \\
{[8]}\end{array}$ & HI Adults & $\begin{array}{l}\text { E-commerce and } \\
\text { Technologies of } \\
\text { Internet }\end{array}$ & $\begin{array}{l}\begin{array}{l}\text { Virtual classroom, Animation, } \\
\text { streaming (sign language) } \\
\text { conference, Chat rooms }\end{array} \\
\end{array}$ & 2005 & Greek \\
\hline $\begin{array}{l}\text { Ng, C.K., Liew, } \\
\text { Y.T., } \\
\text { Saripan, M.I., } \\
\text { Abas, A.F. [9] }\end{array}$ & $\begin{array}{l}\text { Blind and } \\
\text { HI } \\
\text { students }\end{array}$ & $\begin{array}{l}\text { General } \\
\text { Education }\end{array}$ & $\begin{array}{l}\text { Video conference, } \\
\text { Voice-to-text }\end{array}$ & 2007 & Singaporean \\
\hline Nasr, M.M. [10] & $\begin{array}{l}\mathrm{HI} / \mathrm{HOH} \\
\text { students }\end{array}$ & $\begin{array}{l}\text { Chinese Sign } \\
\text { Language }\end{array}$ & $\begin{array}{l}\text { Virtual classroom, Interactive and social } \\
\text { ltools, Video }\end{array}$ & 2010 & Chinese \\
\hline $\begin{array}{l}\text { Hastie, M., } \\
\text { Dornan, D,.[11] }\end{array}$ & $\begin{array}{l}\text { HI } \\
\text { children } \\
\text { fitted with } \\
\text { hearing } \\
\text { technology }\end{array}$ & $\begin{array}{l}\text { Language } \\
\text { (listening and } \\
\text { speaking) }\end{array}$ & $\begin{array}{l}\text { Auditory-Verbal } \\
\text { Therapy (A-VTs) }\end{array}$ & 2011 & Australasian \\
\hline $\begin{array}{l}\text { Debevc, } \\
\text { M.,Stjepanovic, } \\
\text { Z.,Holzinger, } \\
\text { A[12] }\end{array}$ & $\begin{array}{l}\mathrm{HI} \text { and } \\
\mathrm{HOH} \\
\text { people }\end{array}$ & $\begin{array}{l}\text { Computer } \\
\text { Literacy }\end{array}$ & $\begin{array}{l}\text { Video streaming (sign language and } \\
\text { subtitles),Animations }\end{array}$ & 2012 & Slavonic \\
\hline
\end{tabular}

\section{CLOUD COMPUTING FOR E-LEARNING}

Many schools do not have the resources needed to run top level e-learning environments. Due to this lack of infrastructure, Blackboard and Moodle are the most commonly used solutions in the market of e-learning; they also have now versions that are cloud oriented [13]. E-learning is commonly used nowadays on different educational levels: Education, hands on training, academic courses, etc. There are various e-Learning solutions from open source to commercial and there are at least two parties involved in e-Learning solutions: The students and the instructor (teachers). Usually, e-Learning systems are developed as distributed architecture which includes software components like client application, an application server and a database server and the necessary infrastructure components (client computer, communication hardware). Cloud computing provides some major security privileges for individuals and enterprises that are using/developing e-Learning solutions, like the following:

- Improved improbability - it is almost impossible for any individual to allocate machines that store the desired digital documents (tests, exam questions, results).

- Virtualization - makes possible the fast replacement of a cloud located server without intensive costs or damages.

- Centralized data storage - losing a cloud client is no longer a harmful incident while the main part of the applications and data is stored in the cloud, the new client can be connected instantaneously.

The Cloud computing model incorporates technologies like "Virtualization”, “Software-As-A-Service”, that is a brilliant solution to the current problems we are facing in the traditional technology training methodology and the sub-optimal eLearning solutions in common use today. In this research, utilizing (not building) the cloud computing model for eLearning provides several advantages. First and foremost, you get an Internet scale solution that can easily scale to thousands or millions of online concurrent system users. 


\section{SYSTEM OVERVIEW}

The proposed system represents an innovative application based on e-Learning including, new sensors and intelligent techniques for ArSL children tutoring. The systems main module will be hosted on a public cloud as an intelligent service. Figure 2 illustrates the interactive sign language tutoring systems major components, input and output. 3 main services are hosted on the cloud system: Tutoring system, Text-to-Sign module and Sign-to-Text module, Teacher based mood employs a teacher instead of tutoring system. The sign language tutoring system contains two basic service modules:

- Text o sign module: A system that translates input Arabic text to an avatar based ArSL sign.

- Sign Evaluation module: A system that recognize the input of ArSL signs and converts them to Arabic text.

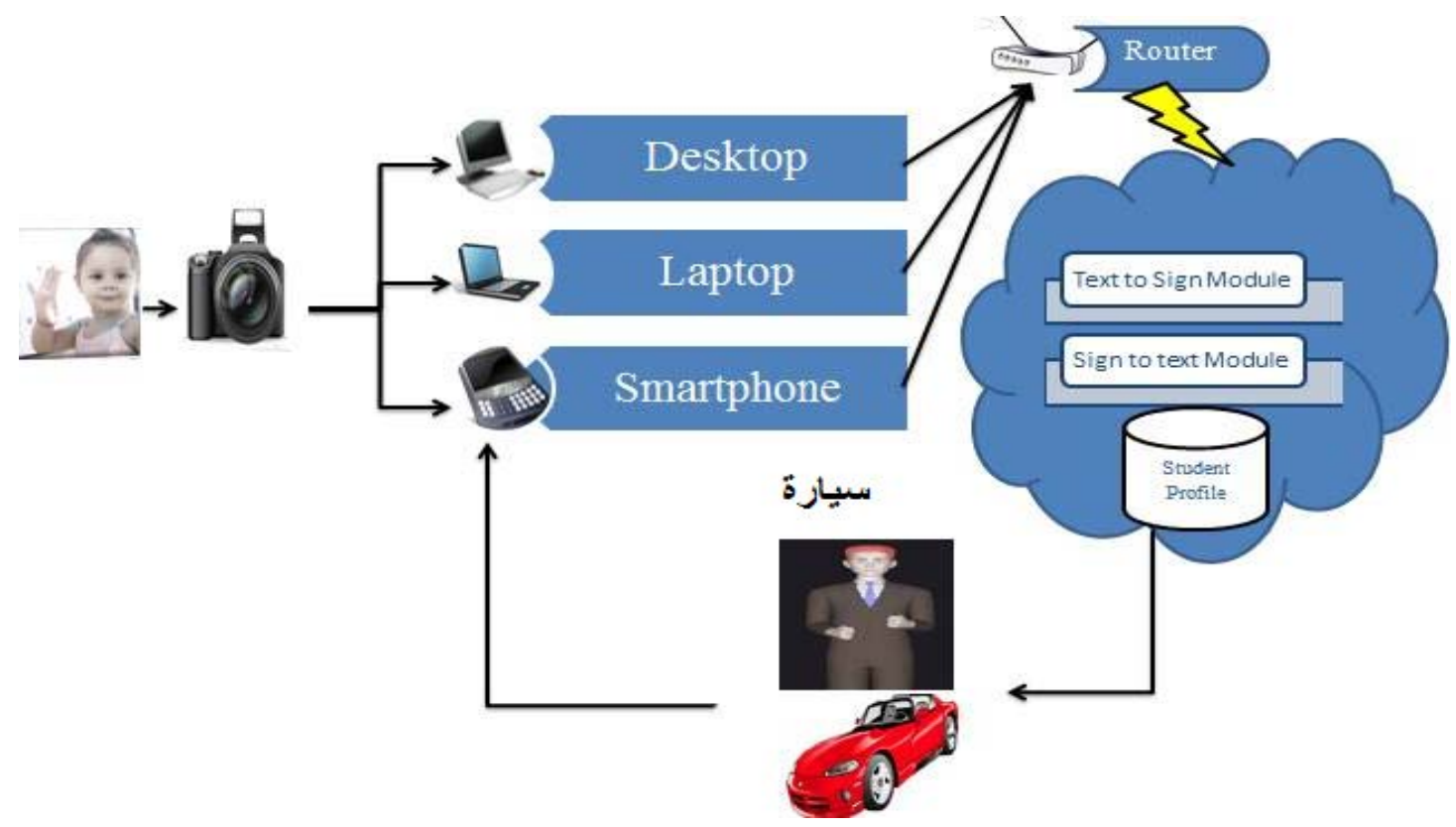

Figure 2: Sign language tutoring systems

The main scenario is as follows: The text to sign module generates the ArSL signs in a cartoon avatar picked by the child himself. The sign is generated and presented with the Arabic text and a picture or a movie that illustrates the meaning. The child repeats the signs against a digital camera (webcam or phone camera). The video is then processed by the "Sign to Text” module which recognizes the performed signs and converts them to Arabic text. The tutoring system assesses the student performance and registers the student score in the students profile database.

\section{A. Sign Evaluation Module (Sign-to-Text Translator)}

The proposed module would be customized to test the student performance for signs. Figure 3 illustrates the employment of the Sign-to-Text module in the e-Learning system. The recognition system is illustrated in Fig 4, starting from input capturing, passing through synchronization, features extraction, recognition and ending with post the processing module. The input synchronization is responsible for time management between heterogeneous sensors at a given point of time, the system captures the simultaneous movement and shape for hands, face and body. After that the Artificial Neural Network (ANN) (Multiplicative Neural Network) is employed to both feature extraction and classification for static postures. After the discrete static postures are classified, they are re-collected and combined to form a complete dynamic gesture (sign). Obviously due to environment and external factors, the recognition accuracy degrades with any slice change. A post processing module based on Natural Language Processing rules and sign language understanding is proposed to detect and correct expected errors resulting from recognition systems. 


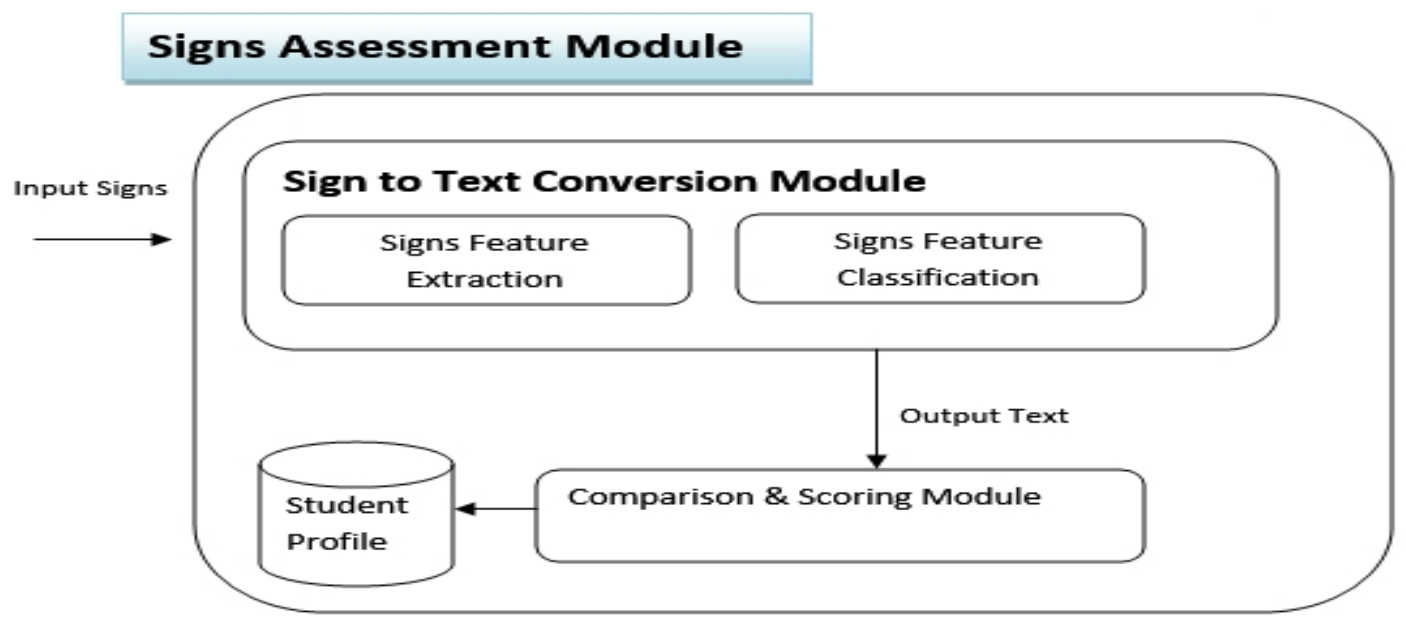

Figure 3: Sign translation module

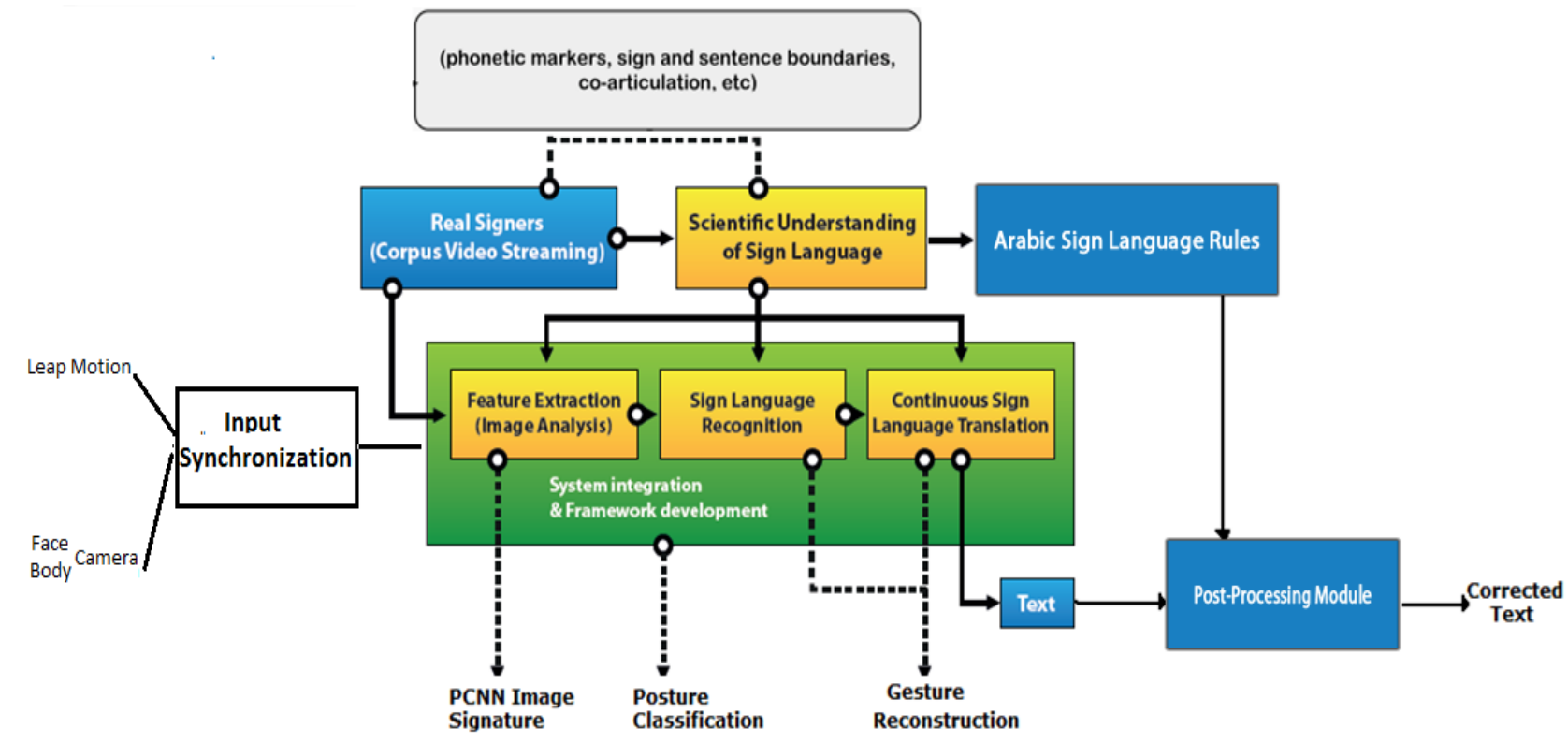

Figure 4: Sign Recognition System.

\section{B. Text to Sign Module}

Text-To-Sign service enables the teacher or the tutoring system to convert words or phrases to animating avatars that perform the signs. The input is an Arabic text and the output is the sign language performed by a cartoon like avatar. The module is composed of sub-modules; each is responsible for a specific task, Fig.5:

\section{- NLP Processing Module}

This includes a customization for readymade tools that enable analyzing the input of Arabic text, dividing the input phrase and performing lexical and syntactical analysis.

\section{- ArSL Transcription Module}

In ArSL, a sign loosely corresponds to a word but can express entire concepts and complex phrases. Finger spelling is used to spell out proper names and technical terms. While additional elements may be present, there is a consensus among ArSL linguists that the shape of the hand (hand shape), as well as its location and movement are essential elements of a sign and most signs are a sequence of these elements. Hand shapes in particular are configurations of the hand.

The transcription module is responsible for generating a computer standard description of a sign, describing the following:

0 Hand shape. 
o Facial Expressions.

o Body Movements.

o Eyes Movements.

o Mouth movements.

\section{- Sign Synthesizer Module}

This module employs a chosen cartoon avatar to perform the signs description generated by the sign transcription module. The challenge in building this module is making the transition between signs as smooth as possible.

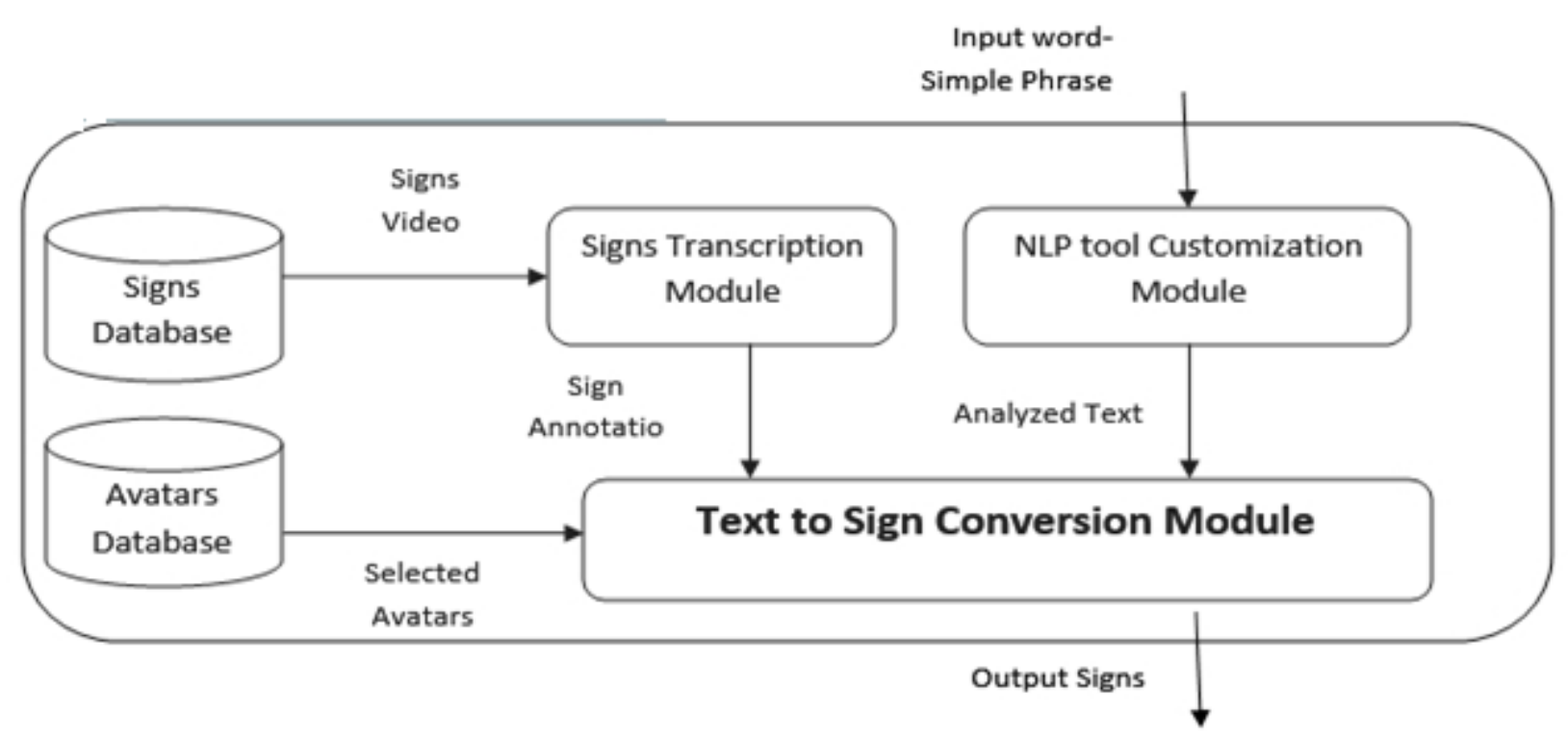

Figure 5: Text-to-Sign module

There are two major approaches for sign language synthesizing systems, Rule based approach and the Data driven approach. The Data driven approach or the corpus based approach as another name, can be categorized as Statistical Machine Translations (SMT) [14] and Example Based Machine Translations (EBMT) [15] methodologies .The corpus based approach requires a pre-requisite corpus to work on it and the accuracy of the transition depends on the corpus contents size. Meanwhile, the Rule based approach is based on linguistic rules and has two different techniques: The direct path and indirect path. The direct path technique is used in bilingual dictionaries that require translating a word to a corresponding word without any analysis of the syntactic structures of the input text or the relationship between words. The indirect path approach is the most complicated and widely used approach in machine translation systems. This approach is used to analyze the syntactic structure of the input text and create an intermediate representation of it and then generate a target language text from it. In the proposed system we will follow a new hybrid (Data Driven and rule based) approach for two reasons:

- The availability of large scale Arabic corpus facilitates the applying of a Data driven approach with high accuracy.

- $\quad$ The rule based approach provides a helpful addition due to its nature, which is based on linguistic analysis.

\section{EXPERIMENT \& RESULTS}

The Experiment has been conducted initially on two $4^{\text {th }}$ grade students in primary school. From the official dictionary which contains 1216 signs, 50 signs were exploited. The tackled signs were selected based on facial expression absence. For each student, a private profile has been created to track the students score. Table 3 shows the chosen signs. 
TABLE 3

EXPERIEMNT SIGNS

\begin{tabular}{|c|c|c|c|c|c|}
\hline Index & $\begin{array}{l}\text { Word in } \\
\text { Arabic }\end{array}$ & $\begin{array}{l}\text { Word in } \\
\text { English }\end{array}$ & Index & $\begin{array}{l}\text { Word in } \\
\text { Arabic }\end{array}$ & $\begin{array}{l}\text { Word in } \\
\text { English }\end{array}$ \\
\hline 1 & ملابس & Clothes & 26 & ملابس نوم & $\begin{array}{l}\text { Sleeping } \\
\text { clothes }\end{array}$ \\
\hline 2 & بنطلون & Pants & 27 & جاكبت & Jacket \\
\hline 3 & تي شيرت & t-shirt & 28 & الدعالج & Processor \\
\hline 4 & دول & Countries & 29 & رقاقة الذاكرة & Memory \\
\hline 5 & قار/ت & Continentals & 30 & الشبكة & Network \\
\hline 6 & محبطلات & Oceans & 31 & اب & Father \\
\hline 7 & Ll & $\mathrm{Me}$ & 32 & ام & Mother \\
\hline 8 & انت & You & 33 & خال & Uncle \\
\hline 9 & هو & $\mathrm{He}$ & 34 & جل & Grandfather \\
\hline 10 & هي & She & 35 & خالة & Aunt \\
\hline 11 & م & They & 36 & جلة & Grandmother \\
\hline 12 & نحن & $\mathrm{We}$ & 37 & مليار & Billion \\
\hline 13 & في & In & 38 & مليون & Million \\
\hline 14 & علي & On & 39 & الف & Thousand \\
\hline 15 & شاشة & Screen & 40 & حبوان & Animal \\
\hline 16 & رقاقة & Chip & 41 & اسد & Lion \\
\hline 17 & سلك & Wire & 42 & دبب & Bear \\
\hline 18 & مطبخ & Kitchen & 43 & ثعبان & Snake \\
\hline 19 & بحر & Sea & 44 & طائرة & Plane \\
\hline 20 & نفق & Tunnel & 45 & مطار & Airport \\
\hline 21 & شارع & Street & 46 & سائق & Driver \\
\hline 22 & مدرس & Teacher & 47 & وزير & Minister \\
\hline 23 & ضابط & Officer & 48 & رئبيس & President \\
\hline 24 & كلية & College & 49 & خباط & Tailor \\
\hline 25 & صحة & Health & 50 & نعناع & Mint \\
\hline
\end{tabular}

The signs are performed using 4 different people, the two sign sets are used as training sets and the other two are used as test sets. The implementation details of the MLP network are: The Input layer has 20 neurons, 1 hidden layer with 35 neurons, 50 neurons in the output layer, the learning rate is 0.0001 and the momentum factor is 0.2 .

Figure 6 illustrates a demo for ArSL recognizer.

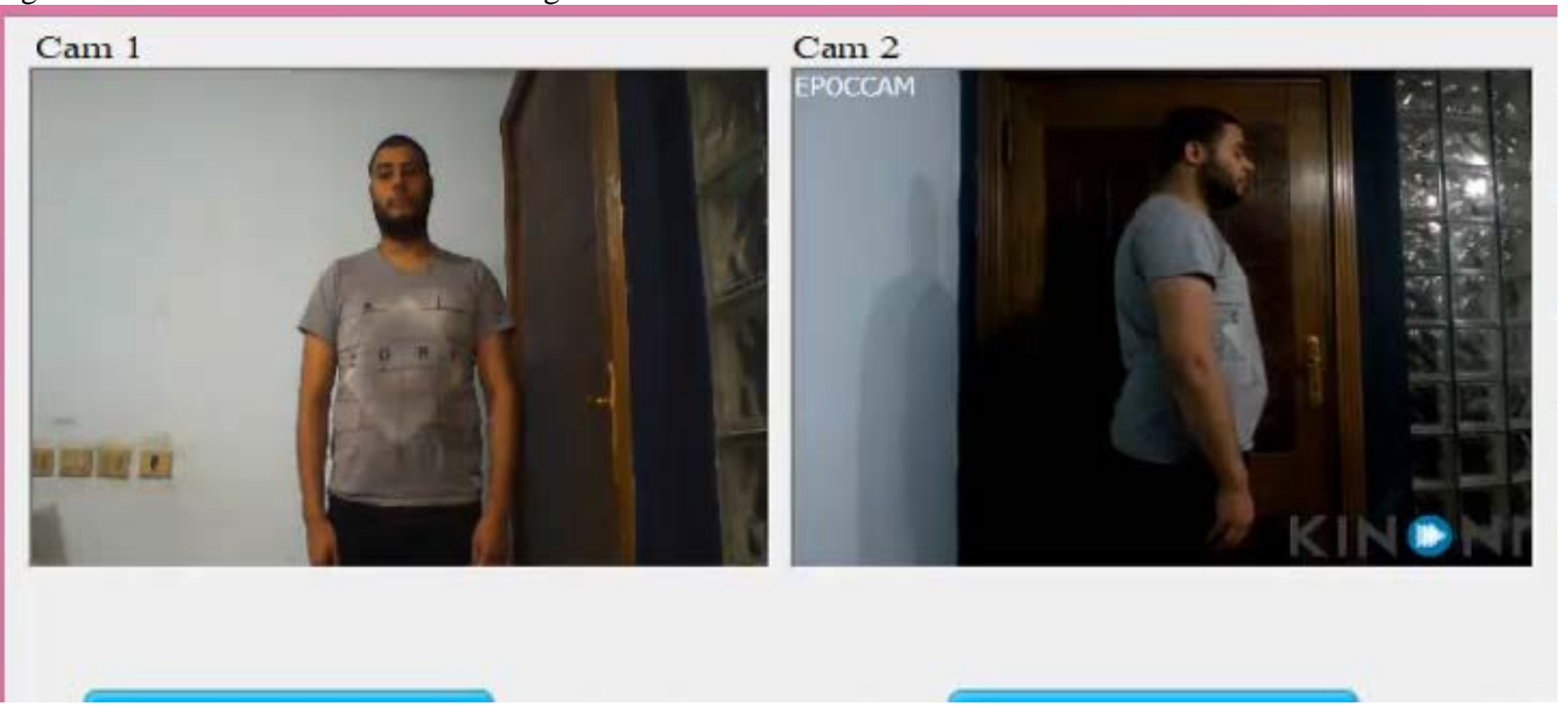




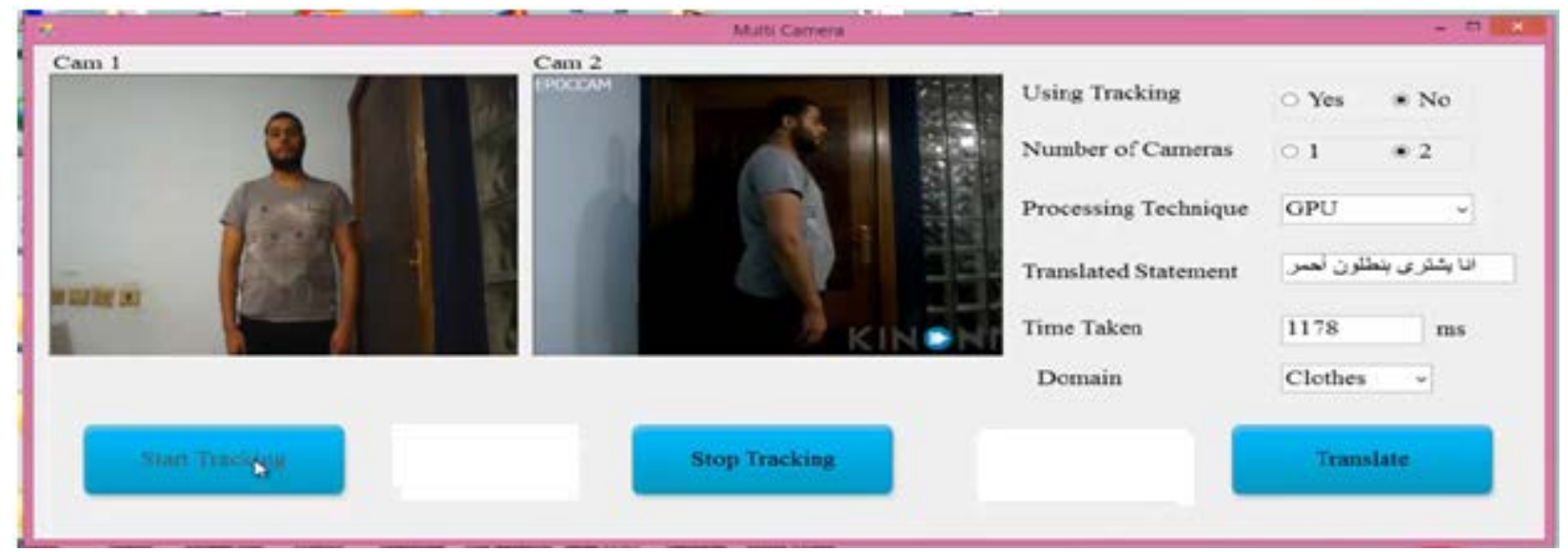

Figure 6: ArSL recognition module

The demo input could be digital data from leap motion sensors, a single digital camera or two cameras. The recognition accuracy for the two students was $88 \%$. Figure 7 illustrates a demo for text to sign translator.

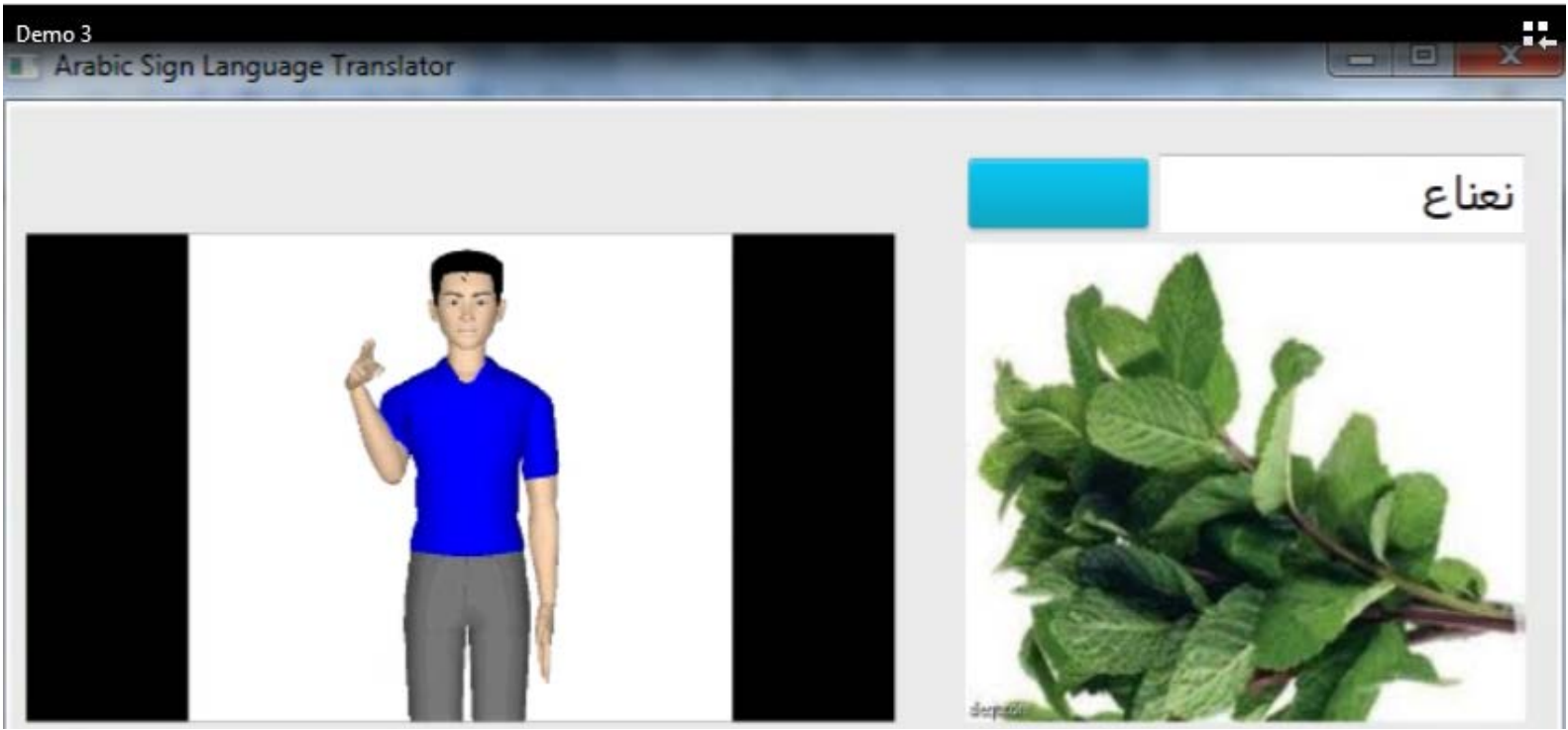

Figure 7: ArSL text to sign module

The demo shows the sign text, image for the meaning and 3D avatar performing the sign. The scoring system is still the primarily phase; it counts the average number of repeating for each sign performance.

\section{CONCLUSION AND DISCUSSION}

The proposed system is to provide an e-Learning solution that presents enhanced pedagogical aspects of the e-Course for Arabic Sign Language (ArSL). The proposed systems services will be hosted on a public cloud for security and resource management purposes. 3 basic services are developed; sign to text, text to sign and simple scoring system and the system is tested on 2 students for 50 signs reaching $88 \%$ translation accuracy also the student can do the signing against a digital camera or a leap-motion sensor. The system can be a base for a complete paradigm for building e- Courses for HI children. 


\section{BIOGRAPHY}

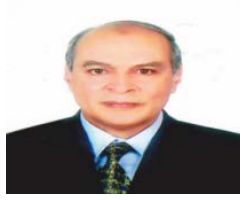

Prof. Dr. Mohamed Fahmy Tolba is a Professor of Scientific Computing, FCSIS (1996-Present). Dr. Tolba has more than 150 publications in the fields of AI, Image Processing, Pattern Recognition, OCR, Scientific Computing, Simulation and Modeling. Also Dr. Tolba has supervised more than 50 M.Sc. and 25 Ph.D. degrees in Ain Shams University and other Egyptian Universities.

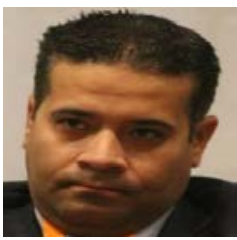

Dr. Ahmed Samir is a Lecturer at the Faculty of Computer and Information Science, Ain Shams University, Cairo, Egypt. His research interests: Image Processing and, pattern recognition and AI. He worked in Arabic Sign Language Recognition field from 2004 till now.

\section{REFERENCES}

[1] A. Samir Elons, M. Aboul-Ela and M.F Tolba." 3D Object Recognition Using Multiple 2D Views for Arabic Sign Language," Journal of Experimental \& Theoretical Artificial Intelligence, vol. 25, no. 1,pp. 119-137, 2013

[2] Schwartz, B. L. Sources of information in meta memory, Judgments of learning and feelings of knowing. Psychonomic Bulletin and Review, 3rd ed, pp. 357 - 375, 1994.

[3] S. Samreen and M. Benali, “2009.

[4] M. Mohandes, “Arabic sign language recognition,” presented at the Int. Conf. Imag. Sci., Syst. Technol., Las Vegas, NV, USA, 2001.

[5] N. El-Bendary, H. M. Zawbaa, M. S. Daoud, A. ella Hassanien, and K. Nakamatsu, “ArSLAT: Arabic sign language alphabets translator,” in Int. Conf. Comput. Inf. Syst. Ind. Manag. Appl., pp. 590-595, 2010.

[6] A. S. Elons, M. Abull-ela, and M. F. Tolba, "Neutralizing lighting non-homogeneity and back-ground size in PCNN image signature for Arabic sign language recognition,” Neural Comput. Appl., vol. 22, no. 1, pp. 47-53, May 2013.

[7] F. F. Al Mashagba, E. F. Al Mashagba, and M. O. Nassar, "Automatic isolated-word Arabic sign language recognition system based on time delay neural networks: New improvements,” J. Theor. Appl. Inf. Technol., vol. 57, no. 1, pp. 42-47, Nov. 2013

[8] A. S. Drigas, J. Vrettaros, L. Stavrou, D. Kouremenos," E-learning Environment for Deaf people in the E- commerce and New Technologies Sector," WSEAS Transactions on Information Science and Applications, Issue 5, vol. 1, p.1189, November 2004.

[9] Ng, C.K, Liew, Y. T., Saripan, M. I., \& Abas, A. F, "Education for all: disabled friendly Flexi e-learning system" in Proc. of AEESEAP regional symposium on engineering education , pp. 120-124, 2007.

[10] Nasr, M. "An enhanced e-learning environment for Deaf / HOH pupils," in Proc. $2^{\text {nd }}$ International Conference on Computer Technology and Development (ICCTD) IEEE , pp. 724-727. , 2010.

[11] Hastie, M., Dornan, D., Chen, N. S., \& Smith, R. "An Australasian e-Learning solution to overcome the global pandemic that is paediatric hearing loss," Retrieved from http://iclll2011.oum.edu.my/extfiles/pdf/An Australasian ELearning Solution To Overcome The Global Pandemic That Is Paediatric Hearing Loss.pdf, 2010.

[12] Debevc, M., Stjepanovič, Z., \& Holzinger, A. "Development and evaluation of an e-learning course for deaf and hard of hearing based on the advanced Adapted Pedagogical Index method," Journal of Interactive Learning Environments ,vol. 22, no. 1, pp. 35-50, 2014.

.[13] D.Manongga, W. Herry Utomo, "E-Learning Development As Public Infrastructure of Cloud Computing ," Journal of Theoretical and Applied Information Technology", vol. 62, no.1, 2014.

[14] S. Baldassarri, E. Cerezo, and F. Royo-Santas, "Automatic Translation System to Spanish Sign Language with a Virtual Interpreter," in Proc of the 12th IFIP TC 13 International Conference on Human-Computer Interaction: Part I, Uppsala, Sweden: Springer-Verlag, pp. 196-199, 2009.

[15] B. Sarkar, K. Datta, C.D. Datta, D. Sarkar, S. J. Dutta, I. D. Roy, A. Paul, J.U. Molla, and A. Paul, "A Translator for Bangla Text to Sign Language," in Proc of Annual IEEE India Conference, Ahmed abad, India, pp. 1-4, 2009. 


\section{مقترح بناء بيئة تعليم الكتروني باستخدام لغة الاشارة العربية

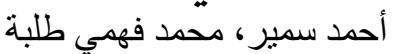

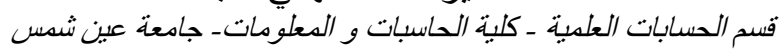

خلاصة:

لا شك ان الوطن العربي يعاني من مشاكل التعليم بشكل ينعكس علي وضعه خصوصا التعليم الموجه لمتحدي الاعاقة بشكل عام و

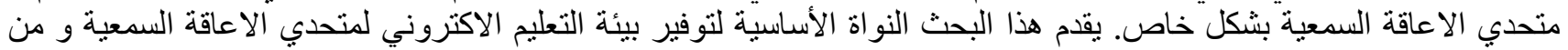

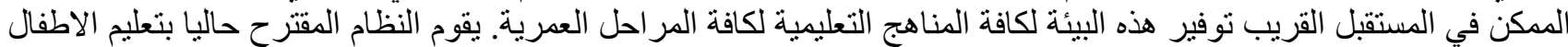
ضعاف السمع لغة الاشارة العربية (50 اشارة) و يقوم الطفل بأدائها و يقيم النظام أداء الطفل للاشئارة. 